\title{
Associations between the home yard and preschoolers' outdoor play and physical activity
}

\author{
Guy P Armstrong ${ }^{\mathrm{a}}$, Clover Maitland ${ }^{\mathrm{b}, \mathrm{c}}$, Leanne Lester ${ }^{\mathrm{b}}$, Stewart G Trost $^{\mathrm{d}}$, \\ Gina Trapp ${ }^{\mathrm{a} e}$, Bryan Boruff ${ }^{\prime}$, Mohamed K Al Marzooqia and Hayley \\ E Christian ${ }^{\mathrm{a}, \mathrm{e}, \mathrm{g}}$
}

a School of Population and Global Health, University of Western Australia, Perth

b School of Human Sciences (Exercise and Sport Science), University of Western Australia, Perth

c Centre for Urban Research, RMIT University, Melbourne, VIC, Australia

d Institute of Health and Biomedical Innovation, Centre for Children's Health Research, Queensland University of Technology, Brisbane, Australia

e Telethon Kids Institute, University of Western Australia, Perth

+ School of Agriculture and Environment, University of Western Australia, Perth

g Corresponding author: hayley.christian@uwa.edu.au

\section{Article history}

Publication date: March 2019

Citation: Armstrong GP, Maitland C, Lester L, Trost SG, Trapp G, Boruff B, Al Marzooqi MK, Christian HE. Associations between the home yard and preschoolers' outdoor play and physical activity. Public Health Res Pract. 2019;29(1):e2911907. https://doi.org/10.17061/phrp2911907

\section{Key points}

- Preschoolers' home-based outdoor play was positively associated with yard size, lawn quality, number of types of fixed and portable play equipment, natural features and play areas

- Each additional type of fixed play equipment present in the yard was associated with an additional 5 minutes of outdoor play per day

- The home-yard space is an important behaviour setting for young children's active play

\section{Abstract}

Objectives and importance of study: Young children's outdoor play mostly occurs within the home-yard space, yet the influence of the home yard on preschoolers' outdoor play and physical activity is poorly understood. We investigated the relationships between home-yard features and home-based outdoor play and physical activity in preschoolers (2-5 years old).

Study type: Cross-sectional observational study.

Methods: The PLAY Spaces and Environments for Children's Physical Activity (PLAYCE) study (2015-2017) included 1596 children aged 2-5 years attending early childhood education and care (ECEC) services throughout metropolitan Perth, Western Australia. In this study, a subsample of 224 parents from the PLAYCE study completed an online questionnaire about home-yard features (yard size, lawn quality, natural features, fixed and portable play equipment, and flowers and vegetables/herbs). Accelerometers measured the duration of preschoolers' moderate-vigorous physical activity (MVPA) on non-ECEC days. Parent-reported outdoor play at home, sociodemographic factors and social environment factors were collected via the PLAYCE parent survey. Multiple linear regression models were used to determine associations between home-yard features and preschoolers' outdoor play and physical activity.

Results: Children spent 68.9 (SD 2.2) minutes playing outdoors in the home yard per day, and 93.3 (SD 37.1) minutes in MVPA per day on non-ECEC days. After adjusting for child and parent factors, home-yard features positively associated with outdoor play included yard size, lawn quality, number of types of fixed and portable play equipment, natural features and play areas (all $p \leq 0.05$ ). When all significant home-yard features were placed in a model, only the number of types of fixed play equipment was positively associated with minutes of outdoor play per day $(\beta=5.3, p<0.001)$. 
After adjusting for sociodemographic factors, the number of types of portable play equipment in the yard was positively associated with MVPA minutes per day $(\beta=2.16, p=0.019)$; however, this became nonsignificant after further adjusting for social environment factors.

Conclusions: Features of the home-yard physical environment were positively associated with preschoolers' outdoor play and physical activity. Each additional type of fixed play equipment present was associated with an additional 5 minutes of outdoor play per day. These findings suggest that the home-yard space has the potential to facilitate increased outdoor play in young children. Further research is warranted to explore causal relationships between home-yard attributes and young children's outdoor play and physical activity.

\section{Background}

Participation in physical activity is associated with numerous health and developmental benefits in young children, including healthier weight status, improved bone health, improved cardiovascular fitness, and improved motor, cognitive, emotional and psychosocial development. ${ }^{1}$ To gain these benefits, the Australian Government recommends that preschoolers spend at least 3 hours per day in a variety of physical activities, with at least 1 hour per day in energetic play. ${ }^{2}$ However, only $34 \%$ of children aged $2-5$ years achieve the recommended 3 hours of total physical activity per day. ${ }^{3}$ With one in five Australian preschoolers now considered to be overweight or obese ${ }^{4}$, identifying ways to increase physical activity in this age group is a public health priority.

One of the most significant determinants of children's physical activity levels is time spent outdoors. ${ }^{5} \mathrm{~A}$ systematic review of the relationship between outdoor play and health in children revealed that outdoor play has positive effects on child health indicators and behaviours, especially physical activity. ${ }^{6}$ International studies report that preschool children spend approximately 1 hour per day playing outdoors. ${ }^{7,8}$ In Australia, parent-reported data suggest that children aged $2-4$ years spend an average of 174 minutes per day playing outdoors. ${ }^{9}$ Given that outdoor play accounts for a significant proportion of preschoolers' overall level of physical activity ${ }^{10}$, further research is required to determine the factors associated with preschoolers' outdoor play in the environmental settings where they spend their time.

Different settings in which young children's outdoor play and physical activity occur include the home, early childhood education and care (ECEC), and community facilities such as parks, playgrounds, recreation centres and swimming pools. ${ }^{11}$ Given that preschoolers depend on their parents for transport to and from places where they can be physically active, the home environment provides an accessible and convenient setting where they can be physically active and play. ${ }^{12}$ However, most research has focused on the influence of community spaces or ECEC services on preschoolers' physical activity. ${ }^{3,11}$ Findings from these studies have highlighted the importance of the physical environment on young children's physical activity. A systematic review of the correlation between ECEC physical environment and preschoolers' physical activity identified that the size of the outdoor play space and play equipment were key correlates of preschoolers' physical activity while attending care. ${ }^{13}$ Several small intervention studies have also found that the 'naturalisation' of ECEC outdoor areas and community playgrounds promotes more outdoor play time in preschoolers. ${ }^{14-18}$

To date, only a handful of studies have explored the influence of the home-yard space on children's physical activity, and most studies examined only limited features of the home yard. Two studies reported homeyard size to be associated with increased outdoor play in preschoolers ${ }^{19,20}$, while other studies reported no association. ${ }^{12,21}$ Two of these studies also examined the association between yard play equipment and preschoolers' outdoor play ${ }^{12,20}$ with conflicting results. This may be because the studies used different measures to capture outdoor play and yard play equipment, as well as different study designs (cross-sectional versus longitudinal). Overall, these studies were limited by the small number of home-yard features examined (yard size and play equipment only). The aim of our study was to examine the relationship between features of the homeyard space - including vegetation, natural features, and lawn presence and quality - and preschoolers' outdoor play and objectively measured physical activity. 


\section{Methods}

\section{Study design}

The cross-sectional, observational PLAY Spaces and Environments for Children's Physical Activity (PLAYCE) study investigated the relative and cumulative influence of the ECEC, home and neighbourhood environment on preschoolers' physical activity. ${ }^{22}$ Full details of the PLAYCE study methods have been published. ${ }^{22}$ Briefly, between 2015 and 2017, 1596 preschoolers aged 2-5 years and their parents were recruited from 104 randomly selected ECEC centres across metropolitan Perth, Western Australia. The sampling and recruitment of centres was stratified by socio-economic area (low, medium and high) and the size of the centre. Consent was obtained from centre directors (38\% response rate), and then parents of preschoolers attending the ECEC centre (67\% response rate). Exclusion criteria included: child attending full-time school, and any intellectual, emotional, physical or behavioural disabilities which could influence the child's participation in physical activity. Ethics approval was granted by the University of Western Australia Human Research Ethics Committee (\#RA/4/1/7417).

\section{Participants and procedure}

All parents who consented to participate in the PLAYCE study were provided with a PLAYCE parent survey and an accelerometer, to be worn by their child for 7 days, with a diary and instructions. The completed survey and accelerometer were returned to the ECEC centre at the end of the data collection period. Parents indicated their willingness to participate in future PLAYCE-related substudies in the PLAYCE parent survey. For this study, 'willing' parents ( $n=440)$ were emailed an invitation to participate and a unique link to a short online survey about their home yard (see 'Home-yard measures'). A total of 224 completed the online home-yard survey (51\% response rate).

\section{Home-based outdoor play time and physical activity measures}

The PLAYCE parent survey included the Burdette et al. ${ }^{10}$ Outdoor Playtime Checklist, which was developed to measure the amount of time preschoolers spend in home-based outdoor play. The item 'On a typical day, how much time does your child spend playing in the yard or street around your house' (with response options of 0 , $1-15,16-30,31-60,>60$ minutes) was used. The survey asked parents to not include time spent playing outdoors at ECEC or kindergarten, thus the responses generally related to non-ECEC days. This measure has been shown to correlate with objectively measured (via accelerometry) preschooler physical activity levels. ${ }^{10}$ It was assumed that the outdoor play variable would capture all intensities of physical activity (light, moderate and vigorous).

The time that preschoolers spent being physically active was assessed over 7 days using ActiGraph GT3X+ accelerometers worn on the right hip. ${ }^{22}$ These devices exhibit moderate to good reliability and high validity for assessing moderate-vigorous physical activity (MVPA) in young children. ${ }^{23}$ Established cut-off points were used to determine daily time spent in MVPA ( $\geq 420$ counts per 15 seconds). ${ }^{23}$ Non-wear time was defined as intervals with at least 20 consecutive minutes of zero counts, with allowance for up to 2 minutes of counts below 200 counts per 15 seconds. Accelerometer diaries identified days of ECEC attendance. Participants were included in analyses if they had valid data for at least 8 hours of wear time on at least one non-ECEC day. Minutes of MVPA per nonECEC day was used as the outcome variable so that associations between home-yard features and higher intensity physical activity could be examined.

\section{Home-yard measures}

The online survey included questions from the HomeSTEAD Inventory, which is a reliable tool for measuring the presence of natural features and play areas (e.g. trees, gardens, water features; paved play areas, decks, grassed areas; range 0-14), fixed play equipment (e.g. climbing structures, cubby houses, sandboxes, trampolines; range 0-11) and portable play equipment (e.g. different types of balls, frisbees, buckets or shovels, scooters, bikes; range 0-19) in the home yard. ${ }^{24}$ Minor modifications were made to the wording of some items to ensure relevance for the Australian context. Items from existing tools were used to measure the number of different types of flowers, herbs and vegetables present in the home yard (continuous scale truncated at 30). ${ }^{25,26}$ Lawn quality was assessed on a five-point Likert scale ('terrible', 'poor', 'fair', 'good', 'excellent'). ${ }^{27}$ The area in square metres $\left(\mathrm{m}^{2}\right)$ of front, back and/or other yard spaces was reported if known; otherwise parents were instructed to estimate (as accurately as possible) the width and length of their yard space(s) in 1-metre steps.

\section{Confounders}

Child age and sex, maternal age and education, parentreported child preference for physical activity, parentperceived importance of physical activity for their child, and family social support for the child's physical activity were collected via established items in the PLAYCE parent survey. ${ }^{22}$ Income details were not collected, as education and income levels are highly correlated measures of socio-economic status.

Accelerometer wear time was included when examining the association between home-yard features and preschoolers' MVPA on non-ECEC days. 


\section{Statistical analysis}

All analyses were conducted using SPSS (Armonk, NY: IBM; Version 23). Participants with missing accelerometry data $(n=43)$ were included in analyses of outdoor play only. Unreported or outlier yard sizes were treated as missing data $(n=9)$. Bivariate linear regression was used to determine the unadjusted association between each of the home-yard variables and: 1) minutes per day of home-based outdoor play; and 2) minutes of MVPA per non-ECEC day (Model 1). Model 2 included analyses adjusted for child age and sex, and maternal education (and non-ECEC day accelerometer wear time for MVPA). Model 3 further adjusted for social environment factors associated with children's physical activity: child preference for physical activity, parent perceptions of the importance of physical activity for their child and family social support for the child's physical activity. A final single linear regression model including all significant home-yard variables from Model 3 and all adjustment variables was run to identify which home-yard variables were independently associated with preschoolers' homebased outdoor play only (Model 4). Only 'total yard size' (not frontyard size or backyard size) was included in Model 4. A final Model 4 was not run for non-ECEC day MVPA since no home-yard variables remained significant after adjusting for sociodemographic and social environment factors. Models were run with and without adjusting for the ECEC centre children attended; however, there was no effect on the findings. Moreover, because we adjusted for individual parent level of education, arealevel socio-economic status was not included in models.

\section{Results}

\section{Participant and yard characteristics}

The average age of child participants $(n=224)$ was 2.7 years, and $54 \%$ were male (see Supplementary Table 1, available from: research-repository.uwa.edu. au/en/datasets/supplementary-tables-for-associationbetween-the-home-yard-on-pre). On average, parents reported that their preschooler played outdoors in the home yard for 68.9 minutes per day (SD 2.2). Preschoolers did on average 93.3 minutes per day (SD 37.1) of MVPA when not at ECEC. Almost all (92\%) parents who completed the survey were mothers and $69 \%$ had a tertiary qualification. Over half of parents (57\%) believed that the participation of their child in physical activities and sports was 'very important'. On average, families 'sometimes' provided social support for their child to participate in physical activity, and 'agreed' their child prefers to be physically active.

The distribution of total yard size was positively skewed with a median size of $160 \mathrm{~m}^{2}$ (range 0-1700 $\mathrm{m}^{2}$ )
(Supplementary Table 1, available from: researchrepository.uwa.edu.au/en/datasets/supplementarytables-for-association-between-the-home-yard-on-pre). Median sizes for frontyards and backyards were $51 \mathrm{~m}^{2}$ and $78 \mathrm{~m}^{2}$, respectively. Of the $88 \%$ of families with lawns, two-thirds believed their lawn to be of 'good' or 'excellent' quality. Sixty per cent of participants reported having either a designated flower or herb/vegetable garden, with the typical household growing on average 4.6 (SD 5.3) different types of herbs/vegetables and 6.5 (SD 7.2) different types of flowers. On average, yards included 3.5 (SD 2.3) different types of fixed play equipment, 8.6 (SD 2.8) different types of portable play equipment, and 7.9 (SD 2.3) different types of natural features and play areas.

\section{Associations between home-yard features and home-based outdoor play}

After adjusting for sociodemographic and social environment factors, all home-yard features, except the number of types of flowers and types of herbs/ vegetables, were positively associated with the minutes per day preschoolers spent in home-based outdoor play (see Supplementary Table 2, Model 3, available from: research-repository.uwa.edu.au/en/datasets/ supplementary-tables-for-association-between-the-homeyard-on-pre). For every additional $11 \mathrm{~m}^{2}$ of frontyard $(\beta=0.09, p=0.003), 17 \mathrm{~m}^{2}$ of backyard $(\beta=0.06$, $p<0.001)$ and $25 \mathrm{~m}^{2}$ of total yard space $(\beta=0.04$, $p<0.001)$, preschoolers spent an additional minute per day playing outdoors. For every additional type of natural feature and play area present, preschoolers spent an additional 5 minutes per day playing outdoors $(\beta=5.19$, $p<0.001$ ). Each additional type of fixed and portable play equipment present in the yard was associated with an additional 7 minutes $(\beta=6.60, p<0.01)$ and 3 minutes $(\beta=3.32, p=0.001$ ) of outdoor play per day, respectively. For every one unit increase in perceived lawn quality, preschoolers spent an additional 8 minutes per day playing outdoors ( $\beta=8.05, p=0.006$ ).

When all home-yard variables that were significantly associated with outdoor play in Model 3 (total yard size, natural features and play areas, fixed play equipment, portable play equipment and lawn quality) were included in a single model with sociodemographic and social environment adjustment factors, only the number of types of fixed play equipment remained significantly associated with minutes of home-based outdoor play per day $(\beta=5.33, p<0.001$ ) (Table 2 , Model 4 , available from: research-repository.uwa.edu.au/en/datasets/ supplementary-tables-for-association-between-thehome-yard-on-pre). Each additional type of fixed play equipment present in the yard was associated with an additional 5 minutes of outdoor play per day. 


\section{Associations between home-yard features and non-ECEC day MVPA}

After adjustment for sociodemographic factors, only portable play equipment was significantly associated with preschoolers' MVPA on non-ECEC days (Table 3, Model 2, available from: research-repository.uwa.edu. au/en/datasets/supplementary-tables-for-associationbetween-the-home-yard-on-pre). Each additional type of portable play equipment present in the yard was associated with an additional 2 minutes of MVPA per nonECEC day $(\beta=2.16, p=0.019)$. After further adjusting for social environment factors, the number of types of portable play equipment in the yard was not associated with preschoolers' MVPA on non-ECEC days (Table 3, Model 3).

\section{Discussion}

The results of this study highlight the role of fixed play equipment (e.g. climbing structures, cubby houses, trampolines) as facilitators of home-based outdoor play in preschoolers. We found that each additional type of fixed play equipment in the home yard was associated with an additional 5 minutes per day of preschooler home-based outdoor play. This corresponds to an $8 \%$ increase in preschoolers' daily home-based outdoor play for each type of fixed play equipment present. This association was consistent with our hypothesis.

However, the lack of association between yard size and preschooler home-based outdoor play in the final model was unexpected. It is possible that our parentreported measure of yard size under- or overestimated actual yard size. Alternatively, the total yard area may not correspond to usable space where children can play and be physically active. For example, some yards may include a garden shed, significant plantings or garden beds which would reduce the amount of usable space and opportunity for children's outdoor play. Differences in total compared with usable yard space for play may also help to explain the seemingly conflicting findings in the literature. Although a yard is necessary for yard play ${ }^{19}$ and outdoor play is associated with yard size in some studies ${ }^{20}$, the association between yard size and outdoor play may no longer exist once other yard variables such as fixed play equipment are considered. Most fixed play equipment is large in size and thus requires bigger yard spaces to accommodate it. Further research is needed to determine whether objectively measured usable home-yard space is associated with the presence of fixed play equipment, and young children's outdoor play and physical activity.

Our findings also showed that preschoolers spend on average 69 minutes a day playing in and around their home yard. This is consistent with Australian and international studies ${ }^{12,19}$ and reinforces the importance of the home yard and nearby surroundings for young children's outdoor play and physical activity.
Parents generally perceive the home yard as a safe and supportive environment in which preschoolers can engage in physical activity. ${ }^{28}$ Yet, while the majority of Australian families live in separate houses that include private outdoor space, housing affordability, home building trends towards larger houses and smaller blocks, and the cost of land have reduced the amount of outdoor home-yard space available for play for many young children. ${ }^{29}$ Our results indicate that fixed play equipment, irrespective of yard space, is associated with preschoolers' home-based outdoor play. This may be a strategy that parents can consider to promote preschoolers' outdoor play and physical activity within the home environment, even when yard space is limited. This finding adds new information to the debate around the consequences of 'losing' the Australian suburban backyard in the face of increasing housing density. ${ }^{29}$ While urban densification is vital for sustainable development, children of lower income families, who are typically more limited in their housing choice, may be further disadvantaged by minimal yard space as well as limited resources to purchase play equipment. Thus, governments should consider the inclusion of accessible preschooler-friendly space and equipment for play as part of higher density and new development planning policy.

Natural features and vegetation may be an important facilitator of outdoor play and physical activity in young children. ${ }^{11}$ Our study found that each additional natural feature and play area present in the yard was associated with an additional 5 minutes of home-based outdoor play per day. However, after adjusting for other homeyard variables associated with preschooler outdoor play, the number of types of natural features and play areas was no longer associated with preschooler home-based outdoor play. Approximately $60 \%$ of families had flowers, herbs or vegetables present in their yard, but this was not significantly associated with preschooler outdoor play. Nevertheless, established psychodevelopmental theory ${ }^{30}$ indicates that the natural environment provides developmental benefit for children. Further investigation is warranted to determine what and how specific natural features in the home-yard space facilitate increased outdoor play and physical activity in young children.

On non-ECEC days, preschoolers accumulated, on average, 93 minutes of MVPA per day, with most (82.3\%) achieving the Australian 24-hour movement guideline of at least 60 minutes per day of energetic play (i.e. MVPA). ${ }^{2}$ We found that each type of portable play equipment present in the yard was associated with an extra 2 minutes per day of preschooler MVPA. After adjusting for social environment factors associated with children's physical activity, this association was no longer significant. This indicates that factors such as parental support and perceived importance of physical activity for children explains why some children are more physically active and have yards with more portable play equipment. Parents who perceive physical activity as important for their child may be more likely to purchase 
portable play equipment to provide their child with more opportunity for physical activity at home. Thus, the addition of portable play equipment to the home yard (as an alternative to equivalent fixed equipment) may be a cost-effective strategy for parents wishing to support their child's physical activity at home.

A review of the ECEC correlates of preschooler physical activity found that, although the correlates vary, the most significant influence in this setting is the physical environment. ${ }^{31}$ The presence of an outdoor environment and larger play spaces were strongly associated with preschoolers' physical activity at ECEC. ${ }^{31}$ Other reviews show that natural features, and portable and fixed play equipment are important correlates of preschooler physical activity. ${ }^{32,33}$ Our findings of the associations between home-yard features and young children's physical activity are similar, and suggest that larger play spaces with play equipment and natural features are important for preschooler physical activity regardless of the environmental setting (i.e. ECEC or home).

\section{Limitations}

This study was limited by its cross-sectional design and thus was unable to determine causal relationships between home-yard features and preschoolers' homebased outdoor play and physical activity. Parent report was used to measure outdoor play and home-yard features (including yard size) which may have resulted in responder bias. Although the use of objectively measured non-ECEC day MVPA was a strength of this study, it was limited because it was not specific to the home outdoor environment. Future studies should consider using geographic information systems or remotely sensed imagery to objectively measure total as well as usable yard area. Other home-yard features not measured in this study (e.g. presence of shade sails, pergolas, artificial grass) should also be considered. This sample was highly educated (69\% had a tertiary qualification) and mostly mothers. This may limit the generalisability of the findings to lower socio-economic status families and to children in different household structures. Finally, findings from the Australian context should be applied with caution to other locations as housing densities and the amount of private yard space and public open space vary by region and nation.

\section{Conclusions}

Fixed play equipment in the home yard was positively associated with home-based outdoor play, even after adjusting for sociodemographic and social environment factors. The home-yard space is an important behaviour setting for young children's play, with preschoolers spending 69 minutes per day in outdoor play. In a changing Australian housing landscape, these findings may assist parents to promote home-based outdoor play even when yard space is limited. Intervention studies focused on the provision and diversification of play equipment are required to establish a causal link between home-yard features and preschoolers' active play.

\section{Acknowledgements}

The PLAYCE Study is supported by the Western Australian Health Promotion Foundation (Healthway; No. 24219).

$\mathrm{HC}$ is supported by an Australian National Heart Foundation Future Leader Fellowship (100794). GT is supported by a National Health and Medical Research Council Early Career Research Fellowship (1073233). The National Heart Foundation, Telethon Kids institute, WA Department of Health, WA Department of Local Government, Sport and Cultural Industries, WA Local Government Association, Australian Childcare Alliance (WA), UWA Childcare, Nature Play WA, Goodstart Early Learning, Maragon Early Learning, Sonas Early Learning \& Care, Mercy Care, Great Beginnings Early Education, Jellybeans Child Care \& Kindy, Buggles Early Learning and Kindy and ArborCarbon provided support for the project. Pulan Bai provided administrative assistance. We thank the PLAYCE study parents and their children for participating.

\section{Peer review and provenance}

Externally peer reviewed, commissioned.

\section{Competing interests}

None declared.

\section{Author contributions}

$\mathrm{HC}, \mathrm{CM}, \mathrm{LL}, \mathrm{BB}, \mathrm{GT}$ and ST conceived, designed and managed the PLAYCE study. HC, CM and GA conceived and designed this sub-study. GA developed and tested the home yard online survey and collected the home yard data. ST processed the accelerometry data for analyses. $\mathrm{LL}$ and $\mathrm{GA}$ conducted the data analysis. GA, HC, CM and MA interpreted the data and drafted the manuscript. All authors contributed to manuscript drafts and read and approved the final manuscript. 


\section{References}

1. Carson V, Lee E-Y, Hewitt L, Jennings C, Hunter S, Kuzik N, et al. Systematic review of the relationships between physical activity and health indicators in the early years (0-4 years). BMC Public Health. 2017. 17(5):854.

2. Commonwealth Department of Health. Australian 24-hour movement guidelines for the early years (birth to 5 years): an integration of physical activity, sedentary behaviour, and sleep. Australian Government; 2017 [cited 2019 Feb 14]. Available from: www.health.gov.au/internet/main/ publishing.nsf/Content/DAAD9AEB38F655D6CA257C750 01B546D/\$File/24hrGuidleines-Factsheet-fa-0-5.pdf

3. Christian $\mathrm{H}$, Rosenberg M, Trost S, Schipperijn J, Maitland C, Trapp G, et al. A snapshot of the PLAYCE project: findings from the Western Australian PLAY spaces and environments for children's physical activity study. Supportive childcare environments for physical activity in the early years. Perth, Western Australia: The University of Western Australia, School of Population and Global Health; 2018 [cited 2019 Feb 14]. Available from: www.sph.uwa.edu.au/_data/assets/ pdf_file/0003/3098046/Childs-play_PLAYCE-StudyReport-2018.pdf

4. Australian Institute of Health and Welfare. A picture of overweight and obesity in Australia 2017. Canberra: AlHW; 2017 [cited 2019 Feb 14]. Available from: www. aihw.gov.au/getmedia/172fba28-785e-4a08-ab372da3bbae40b8/ainw-phe-216. pdf.aspx?inline=true

5. Hinkley T, Crawford D, Salmon J, Okely AD, Hesketh K. Preschool children and physical activity: a review of correlates. Am J Prev Med. 2008;34(5):435-41.

6. Brussoni M, Gibbons R, Gray C, Ishikawa T, Sandseter $\mathrm{EBH}$, Bienenstock A, et al. What is the relationship between risky outdoor play and health in children? A systematic review. Int J Environ Res Public Health. 2015;12(6):6423-54.

7. Tomkinson G, Schranz N, Olds T, Boyd R, Evans J, Gomersall S, et al. Physical literacy: do our kids have all the tools? The 2016 Active Healthy Kids Australia report card on physical activity for children and young people. Adelaide: Active Healthy Kids Australia; 2016 [cited 2019 Feb 14]. Available from: www. activehealthykidsaustralia. com.au/siteassets/documents/ahka-2016-long_formreport-card.pdf

8. Grigsby-Toussaint DS, Chi S-H, Fiese BH. Where they live, how they play: neighborhood greenness and outdoor physical activity among preschoolers. Int J Health Geogr. 2011;10(1):66.

9. Australian Bureau of Statistics. Australian health survey: physical activity, 2011-12. Canberra: ABS; 2013 [cited 2019 Feb 6]. Available from: www.abs.gov.au/ausstats/ abs@.nsf/Lookup/4364.0.55.004main+features12011-12
10. Burdette HL, Whitaker RC, Daniels SR. Parental report of outdoor playtime as a measure of physical activity in preschool-aged children. Arch Pediatr Adolesc Med. 2004;58(4):353-57.

11. Christian H, Zubrick SR, Foster S, Giles-Corti B, Bull F, Wood L, et al. The influence of the neighborhood physical environment on early child health and development: A review and call for research. Health Place. 2015;33:25-36.

12. Cleland V, Timperio A, Salmon J, Hume C, Baur LA, Crawford D. Predictors of time spent outdoors among children: 5-year longitudinal findings. J Epidemiol Community Health. 2010;64(5):400-6.

13. Tonge KL, Jones RA, Okely AD. Correlates of children's objectively measured physical activity and sedentary behavior in early childhood education and care services: a systematic review. Prev Med. 2016;89:129-39.

14. Herrington S, Studtmann K. Landscape interventions: new directions for the design of children's outdoor play environments. Landscape and Urban Planning. 1998;42(2-4):191-5.

15. Barbour AC. The impact of playground design on the play behaviors of children with differing levels of physical competence. Early Child Res Q. 1999;4(1):75-98.

16. Dyment JE, Bell AC. Grounds for movement: green school grounds as sites for promoting physical activity. Health Educ Res. 2007;23(6):952-62.

17. Quigg R, Reeder AI, Gray A, Holt A, Waters D. The effectiveness of a community playground intervention. J Urban Health. 2012;89(1):171-84.

18. Luchs A, Fikus M. A comparative study of active play on differently designed playgrounds. J Adventure Educ Outdoor Learn. 2013;13(3):206-22.

19. Marino AJ, Fletcher EN, Whitaker RC, Anderson SE. Amount and environmental predictors of outdoor playtime at home and school: a cross-sectional analysis of a national sample of preschool-aged children attending Head Start. Health Place. 2012;18(6):1224-30.

20. Spurrier NJ, Magarey AA, Golley R, Curnow F, Sawyer MG. Relationships between the home environment and physical activity and dietary patterns of preschool children: a cross-sectional study. Int J Behav Nutr Phys Act. 2008;5(1):31.

21. Carson V, Rosu A, Janssen I. A cross-sectional study of the environment, physical activity, and screen time among young children and their parents. BMC Public Health. 2014;14(1):61.

22. Christian H, Maitland C, Enkel S, Trapp G, Trost SG, Schipperijn J, et al. Influence of the day care, home and neighbourhood environment on young children's physical activity and health: protocol for the PLAYCE observational study. BMJ Open. 2016;6(12):e014058.

23. Pate RR, Almeida MJ, Mclver KL, Pfeiffer KA, Dowda M. Validation and calibration of an accelerometer in preschool children. Obesity. 2006;14(11):2000-6. 
24. Hales D, Vaughn AE, Mazzucca S, Bryant MJ, Tabak RG, McWilliams C, et al. Development of HomeSTEAD's physical activity and screen time physical environment inventory. Int J Behav Nutr Phys Act. 2013;10(1):132.

25. Broomhall M, Giles-Corti B, Lange A. Quality of public open space tool (POST). Perth, Australia: The University of Western Australia, School of Population Health; 2014 [cited 2019 Feb 14]. Available from: www.web.uwa.edu. au/_data/assets/pdf_file/0003/411951/POST_Manual.pdf

26. Little $\mathrm{H}$. Promoting risk-taking and physically challenging play in Australian early childhood settings in a changing regulatory environment. J Early Child Res. 2017;15(1):83-98.

27. Edwards N, Hooper P, Trapp GSA, Bull F, Boruff B, GilesCorti B. Development of a public open space desktop auditing tool (POSDAT): a remote sensing approach. Appl Geogr. 2013;38:22-30.

28. Veitch J, Bagley S, Ball K, Salmon J. Where do children usually play? A qualitative study of parents' perceptions of influences on children's active free-play. Health Place. 2006;12(4):383-93.

29. Hall T. The life and death of the Australian backyard. Victoria: CSIRO Publishing; 2010.
30. Frost JL, Wortham SC, Reifel RS. Play and child development. Upper Saddle River: Pearson/Merrill Prentice Hall; 2008.

31. Tonge KL, Jones RA, Okely AD. Correlates of children's objectively measured physical activity and sedentary behavior in early childhood education and care services: a systematic review. Prev Med. 2016;89:129-39.

32. Dyment JE, Bell AC, Lucas AJ. The relationship between school ground design and intensity of physical activity. Child Geogr. 2009;7(3):261-76.

33. Hodges EA, Smith C, Tidwell S, Berry D. Promoting physical activity in preschoolers to prevent obesity: a review of the literature. J Pediatr Nurs. 2013;28(1):3-19.

\section{Copyright: (C) (i) (5) (2)}

(c) 2019 Armstrong et al. This article is licensed under the Creative Commons Attribution-NonCommercial-ShareAlike 4.0 International Licence, which allows others to redistribute, adapt and share this work non-commercially provided they attribute the work and any adapted version of it is distributed under the same Creative Commons licence terms. See: www.creativecommons.org/licenses/by-nc-sa/4.0/ 


\section{Copyright: (c)(1) (2) (2)}

(C) 2019 Surname et al. This article is licensed under the Creative Commons Attribution-NonCommercial-ShareAlike 4.0 International Licence, which allows others to redistribute, adapt and share this work non-commercially provided they attribute the work and any adapted version of it is distributed under the same Creative Commons licence terms. See: www.creativecommons.org/licenses/by-nc-sa/4.0/ 